\title{
Participação social em programas de coleta seletiva de resíduos sólidos urbanos
}

\section{Social participation in selective collection program of municipal solid waste}

\author{
Jacqueline R. Bringhenti \\ Engenheira Civil e Sanitarista. Mestre e Doutora em Saúde Pública pela Faculdade de Saúde Pública pela Universidade de São Paulo (FSP/USP). \\ Professora e Pesquisadora da Coordenadoria de Engenharia Sanitária e Ambiental do Instituto Federal do Espírito Santo (IFES) \\ Wanda M. Risso Günther \\ Engenheira Civil e Socióloga. Especialista em Engenharia Ambiental, Mestre e Doutora em Saúde Pública pela FSP/USP. \\ Professora e Pesquisadora do Departamento de Saúde Ambiental da FSP/USP
}

\begin{abstract}
Resumo
A efetividade de programas de coleta seletiva requer necessariamente o envolvimento dos cidadãos. Entrevistas realizadas com diferentes grupos populacionais do município de Vitória (ES), empregando metodologia qualitativa e a estratégia do Discurso do Sujeito Coletivo, apontam que a participação voluntária da população nos programas de coleta seletiva é baixa, mas que pode aumentar em longo prazo. A adequação da estrutura operacional implantada para dar suporte ao programa de coleta seletiva e a existência de ações continuadas de divulgação, mobilização e informação são fatores facilitadores. A falta de divulgação dos resultados, a acomodação e o desinteresse da população, o descrédito relativo às ações oriundas do poder público, e a falta de espaço, nas residências para armazenar os resíduos recicláveis, dentre outros, são fatores que dificultam a participação na coleta seletiva.
\end{abstract}

Palavras-chave: resíduos sólidos urbanos; coleta seletiva; participação social; gerenciamento de resíduos sólidos; pesquisa qualitativa.

\section{Abstract}

Selective collection programs effectiveness mandates citizens' involvement. Interviews conducted among different population groups in the municipality of Vitória (ES) - Brazil - by use of qualitative methodology and the Discourse of the Collective Subject strategy point out that population voluntary participation in selective collection programs is low, but can increase in the long run. Adequation of the current operational structure and ongoing awareness, mobilization, and information campaigns are facilitating factors in supporting selective collection programs. Lack of results disclosure, population indifference and lack of action, discredit for governmental actions, and shortage of residential storage areas to accommodate recyclables are obstacles for taking part in selective collection.

Keywords: solid waste; source separation; social participation; solid waste management; qualitative research.

\section{Introdução}

No que pese a ocorrência crescente de programas de coleta seletiva (PCS) no Brasil como política pública municipal, aliada ao discurso da gestão integrada e à globalização do tema, a maior parte das iniciativas e ações de coleta seletiva são de caráter informal (RIBEIRO et al., 2009). Segundo o Sistema Nacional de Informações sobre Saneamento (SNIS), a coleta seletiva informal estava presente em 83\% dos 306 municípios pesquisados (BRASIL, 2007).

Em 2002, a avaliação de 94 PCS de resíduos sólidos urbanos (RSU) no país constatou que a maioria relacionava-se a experiências piloto ou a iniciativas pontuais, organizadas pelo poder público, iniciativa privada, ONGs, associações de moradores ou de bairros e/ou condomínios, que atendiam apenas parcela da área urbana ou eram desenvolvidas em locais específicos como escolas, bairros e condomínios (SEDU, 2002). Ao longo dos últimos anos, este cenário vem se mantendo. Em 2010, a pesquisa Ciclosoft indicava que $8 \%$ dos municípios brasileiros possuíam programas municipais de coleta seletiva com funcionamento regular que cobriam $12 \%$ da população brasileira e $86 \%$ do total dessas iniciativas concentravam-se nas regiões Sul e Sudeste do país (CEMPRE, 2010)

A recém-aprovada Política Nacional de Resíduos Sólidos (BRASIL, 2010) contribuirá para o aumento do número de municípios com PCS, pois incorpora conceitos modernos e indutores como responsabilidade compartilhada pelo ciclo de vida dos produtos e 
logística reversa que pressupõem o envolvimento dos gestores públicos, empresas privadas e a sociedade civil organizada.

Estudo desenvolvido nos Estados Unidos sobre os efeitos das variáveis políticas de gestão na taxa de reciclagem constatou que a existência de legislação específica foi eficaz no aumento da taxa de reciclagem no estado de Minnesota (SIDIQUE; JOSHI; LUPI, 2010b). Entretanto, a efetividade de programas e iniciativas de coleta seletiva requer necessariamente o envolvimento dos cidadãos, considerados, no extremo da cadeia de produção e consumo, os geradores dos resíduos sólidos. Há ainda a necessidade de informação e divulgação dos programas/iniciativas implantados, no que se referem às diretrizes, princípios, instrumentos, práticas e modalidades de coleta adotadas. A comunidade deve ser sensibilizada, motivada e os conceitos e práticas precisam ser assimilados e incorporados no cotidiano da população envolvida, com vistas a assegurar sua operacionalização, viabilidade e continuidade, fatores fundamentais para se atingir os resultados esperados e garantir sua sustentabilidade.

Desde que a questão socioambiental vem se impondo como tema de relevância na sociedade brasileira, destacando-se o caráter de urbanização e a emergência da problemática urbana, pode-se considerar que o conceito tradicional de participação social tem se ampliado. O conceito primeiro remete à ideia de atuação direcionada para a defesa de direitos e interesses (JACOBI, 2000) ou se refere ao campo político de força social na sociedade civil, cujas ações se estruturam a partir de repertórios criados sobre temas e problemas em conflito, litígios e disputas vivenciadas pelo grupo na sociedade (GOHN, 2000), ou ainda considera a participação como instrumento regulador de um sistema (CARDOSO, 1998). Mesmo os movimentos sociais da contemporaneidade não se reduzem à defesa coletiva de interesses, uma vez que as ações coletivas da sociedade civil têm apresentado mudanças em seu conteúdo, nas suas práticas e nas formas de organização de suas bases (GOHN, 2000). Nesse contexto, foi considerado como participação social, neste artigo, o envolvimento da população em ações do poder público, mais especificamente nas ações de gestão ambiental local; refere-se à disposição e adesão dos indivíduos da comunidade às solicitações do gestor público para gerir a coisa pública. Tal aproximação remete ao exercício da cidadania, que segundo Scherer-Warren (2001) implica em marcar presença na esfera pública, a partir de processos participativos e pressupõe a observação de regulamentações sociais, a convivência societária e, em última instância, o reconhecimento do outro como cidadão. Seriam ações coletivas contemporâneas focadas em ações ambientais, que não se enquadram nas categorias científicas disponíveis (GOHN, 2000), ou ainda, condições de motivação para ações de corresponsabilidade e participação comunitária (JACOBI, 2000).

\section{Participação social na coleta seletiva}

No planejamento da implantação de PCS, uma das principais dificuldades refere-se à mensuração da participação da população, fator importante e determinante do investimento a ser realizado. A participação social depende do perfil socioeconômico e cultural da população, com destaque para aspectos como grau de instrução e acesso à educação não formal. Porém, a adequação do projeto à realidade local, a regularidade no funcionamento da logística implantada e a eficiência da estratégia de marketing para sensibilização e motivação da população são fundamentais. A relação entre comportamento e atitudes da população e o desempenho da reciclagem a partir da coleta seletiva tem sido tema de várias pesquisas em diversas partes do mundo (WANG; RICHARDSON; RODDICK, 1997; MCDONALD; OATES, 2003; BRINGHENTI, 2004; TIMLETT; WILLIAMS, 2008; SIDIQUE; JOSHI; LUPI, 2010a, 2010b).

Timlett e Williams (2008) avaliaram o desempenho da reciclagem de resíduos sólidos domiciliares na Inglaterra a partir de três estratégias para aumentar a participação da população em PCS e melhorar a qualidade dos recicláveis coletados: oferta de incentivos (recompensas); abordagem de feedback, que prevê o retorno aos moradores de eventuais problemas existentes com a separação dos recicláveis por eles executada; e inquéritos porta a porta, para levantamento das razões da não adesão ou da baixa participação. As duas primeiras foram altamente eficazes na redução da presença de rejeitos nos recicláveis, porém a segunda apresenta menor custo de investimento. Entretanto, as três opções avaliadas não resultaram em incremento significativo nas taxas de participação social. Os autores concluíram que a mudança de comportamento é mais eficaz a partir da utilização de métodos simples e de baixo custo que envolvam os moradores e a equipe operacional responsável pela coleta de recicláveis

Estudos de Wang, Richardson e Roddick (1997) enfocam a associação entre as taxas de participação nos programas de reciclagem na Austrália e a quantidade de materiais recicláveis recuperados. Em função da participação, o estudo agrupou as famílias em três categorias - participam regularmente, não podem participar por várias razões e participam com menor frequência - e considerou três modalidades de participação social: grupo cativo, de participação eventual e que não participa, trabalhando com a hipótese que o modo de participação é fator determinante do sucesso dos PCS.

Para testar esta hipótese proposta foi realizada pesquisa qualitativa que buscou conhecer a percepção sobre a questão da coleta seletiva de resíduos sólidos urbanos, de diferentes grupos populacionais do município de Vitória (ES). 


\section{Material e Métodos}

\section{Área de estudo}

O município de Vitória, capital do Estado do Espírito Santo, situa-se em uma ilha com pequena extensão territorial e diversas áreas protegidas e abriga cerca de 300.000 habitantes. Sempre enfrentou dificuldades em alocar áreas para disposição final dos RSU que fossem sanitária e ambientalmente compatíveis com tal finalidade. Ao longo das últimas décadas, a Prefeitura Municipal implantou diversos programas municipais de coleta seletiva.

Em 1998, iniciou-se uma das experiências mais significativas, que atendeu parte da área urbana e envolveu as modalidades: coleta por postos de entrega voluntária (PEVs) e por cooperativas de catadores. A partir de 2002, o programa foi ampliado, passando a incluir, em cerca de $10 \%$ do município, a coleta seletiva porta a porta, este último, paralisado em 2005. Em 2007, ocorreu alteração do tipo de contêiner (PEVs) e do procedimento de triagem dos resíduos coletados, que passou a ser realizado por cooperativas de catadores.

Este cenário, de descontinuidade de PCS, comum em diversos municípios brasileiros, levou a escolher o município de Vitória como estudo de caso.

\section{Delineamento metodológico e amostra}

Para se conhecer os determinantes da participação da população em PCS de RSU foi empregada a técnica do Discurso do Sujeito Coletivo - DSC (LEFÉVRE; LEFÉVRE, 2005). Segundo os autores, "o Discurso do Sujeito Coletivo é uma coletividade falando como se fosse um indivíduo". A técnica pressupõe ser metodologicamente possível expressar o pensamento da coletividade sob a forma de um discurso único, que sintetiza os diversos discursos presentes. Trata-se de um discurso síntese, elaborado na primeira pessoa do singular, a partir dos dados obtidos nos depoimentos dos entrevistados.

A escolha da área de estudo considerou as variáveis: classe social e modalidade de coleta seletiva. Para a classe social utilizou-se a estratificação por renda mensal da família, contabilizada em salários-mínimos (SM), conforme considerada pela Secretaria Municipal de Meio Ambiente - SEMMAM (2002), o que definiu as classes D: até dois SM.; C: de dois a cinco SM; B: de cinco a dez SM; e A: mais de dez SM. As modalidades de coleta seletiva consideradas foram: coleta municipal porta a porta, coleta municipal em PEVs, e coleta executada por cooperativas de catadores, cuja classificação baseou-se em informações disponíveis no município, referentes ao planejamento de ampliação da coleta seletiva (SEMMAM, 2002). Considerando-se que não houve representante da classe $\mathrm{D}$ entre os bairros contemplados com coleta seletiva, o sorteio aleatório dos bairros estudados resultou nas seguintes localidades:

- Mata da Praia (MP): classe A e coleta seletiva por cooperativa de catadores;

- Jardim Camburi (JC): classe B e coleta seletiva porta a porta;

- Praia do Suá (PS): classe B e coleta seletiva por postos de entrega voluntária;

- Jucutuquara (J): classe B e por postos de entrega voluntária;

- Ilha de Monte Belo (IMB): classe C e coleta porta a porta;

- Bairro de Lourdes (BL): classe C e coleta por cooperativa de catadores.

Nos bairros MP e JC, a coleta seletiva havia sido implantada desde 1998 e nos demais estava em fase de implantação no momento da coleta de dados.

Em cada um dos seis bairros sorteados, foram realizadas 8 entrevistas, totalizando 48 entrevistados, segundo a amostra intencional: 2 moradores com idade entre 16 e 30 anos; 2 moradores entre 30 e 59 anos; 2 moradores com 60 anos ou mais; 1 líder comunitário ou representante político local; e 1 comerciante ou industrial. No caso dos moradores, foi entrevistado um representante do sexo masculino e outro do sexo feminino, para todas as faixas etárias.

O perfil da amostra foi definido por critérios que visavam inserir: pessoas com idade para votar e serem votadas em eleições de representantes políticos e, portanto, que podem, desta forma, interferir nas decisões sobre políticas públicas; grupo representativo de entrevistados que assumem a administração da residência, como as donas de casa, geralmente responsáveis pelo gerenciamento dos resíduos sólidos no núcleo familiar; grupo representativo dos chefes de família, responsáveis pelo sustento da casa; grupo dos formadores de opinião local; e grupo dos aposentados, potenciais parceiros de programas dessa natureza por sua maior disponibilidade de tempo livre.

Seguindo todas as recomendações da ética em pesquisa, a investigação foi aprovada pelo Comitê de Ética em Pesquisa da Faculdade de Saúde Pública da Universidade de São Paulo.

\section{Coleta e análise de dados}

Os dados foram coletados em entrevistas individuais seguindo roteiro semiestruturado, realizadas por entrevistadores previamente capacitados; foram gravadas e transcritas posteriormente. $\mathrm{Na}$ análise dos dados, os resultados foram tabulados em função da ideia central (IC) e da ancoragem síntese (A), figuras metodológicas da análise do DSC (LEFÉVRE; LEFÉVRE, 2005), conceituados como: IC - descrição, de maneira mais sintética e precisa possível, dos depoimentos do grupo de indivíduos 
entrevistados, que compõem o sujeito coletivo (S) ao qual a ideia central está referenciada; A - descrição, de maneira sintética, de afirmações genéricas que representam crenças de senso comum, encontradas nas respostas dos entrevistados.

\section{Resultados}

A percepção dos entrevistados sobre as questões: conhecimento sobre coleta seletiva; participação dos programas; descontinuidade dos programas; e as declarações dos entrevistados foram sintetizadas nas Tabelas 1 e 2 , respectivamente.

\section{Conhecimento e participação na coleta seletiva}

O conjunto dos discursos obtidos denota associação entre coleta seletiva, reciclagem e separação dos resíduos sólidos, sendo a coleta seletiva considerada como uma boa medida para a cidade.
A participação nos PCS foi identificada por meio de questionamento aos moradores quanto à sua participação efetiva, à disposição ou não em participar e quais os motivos de sua decisão. Os resultados estão apresentados na Tabela 1.

Os depoimentos mostram as percepções sobre três enfoques principais. O primeiro, que a coleta seletiva refere-se ao lixo e à sua separação (20/48 dos entrevistados):

Coleta seletiva? Ah! Lembrei. É aquele que tem uns troços lá que coloca o lixo de plástico, vidro, papel, papelão, né? Essas coisas...

(PS) A separação do lixo orgânico, inorgânico (JC). Que separa vidro, metal, plástico (BL). Que podem se tornar novas matérias primas $(J)$. A coleta seletiva já está sendo feita na praça próxima. Onde é separado todo tipo de material (MP).

O segundo apresenta a coleta seletiva como auxiliar na solução do problema do lixo (12/48):

Tabela 1 - Conhecimento sobre coleta seletiva e reciclagem de resíduos sólidos urbanos e participação na coleta seletiva: síntese das ideias centrais e ancoragem, por bairro

\begin{tabular}{|c|c|c|c|c|c|c|c|c|}
\hline \multirow{2}{*}{\multicolumn{2}{|c|}{ Ideia central síntese }} & \multirow{2}{*}{ Ancoragem } & \multicolumn{6}{|c|}{ Número de entrevistas por bairro } \\
\hline & & & $M P(n=8)$ & $J C(n=8)$ & PS $(n=8)$ & $J(n=8)$ & IMB $(n=8)$ & $\mathrm{BL}(\mathrm{n}=8)$ \\
\hline \multirow{4}{*}{$\begin{array}{l}\text { Conhecimento } \\
\text { sobre coleta sele- } \\
\text { tiva e reciclagem }\end{array}$} & $\begin{array}{l}\text { Refere-se ao lixo e à sua } \\
\text { separação }\end{array}$ & $\begin{array}{c}\text { Coleta seletiva é a separa- } \\
\text { ção do lixo }\end{array}$ & 4 & 6 & 1 & 2 & 2 & 5 \\
\hline & Refere-se à Prefeitura & $\begin{array}{c}\text { Coleta seletiva é um projeto } \\
\text { da Prefeitura }\end{array}$ & 4 & 2 & - & - & - & - \\
\hline & $\begin{array}{c}\text { É a coleta regular do lixo } \\
\text { domiciliar }\end{array}$ & $\begin{array}{l}\text { Coleta seletiva é a coleta } \\
\text { do lixo doméstico feita pela } \\
\text { Prefeitura }\end{array}$ & - & - & 4 & 3 & 2 & 1 \\
\hline & $\begin{array}{l}\text { Ajuda a resolver o prob- } \\
\text { lema do lixo }\end{array}$ & Mídia & - & - & 3 & 3 & 4 & 2 \\
\hline \multirow{7}{*}{$\begin{array}{l}\text { Participação na } \\
\text { coleta seletiva }\end{array}$} & $\begin{array}{l}\text { Participo da coleta sele- } \\
\text { tiva separando o lixo }\end{array}$ & $\begin{array}{l}\text { Muita coisa que vai para o } \\
\text { lixo se aproveita }\end{array}$ & 3 & 3 & 4 & - & - & - \\
\hline & $\begin{array}{l}\text { Participo da coleta sele- } \\
\text { tiva junto à comunidade }\end{array}$ & $\begin{array}{c}\text { Participar da coleta seletiva } \\
\text { é exercer a } \\
\text { cidadania }\end{array}$ & 1 & - & 1 & - & - & - \\
\hline & $\begin{array}{l}\text { Participaria da coleta sele- } \\
\text { tiva pelo meio ambiente }\end{array}$ & $\begin{array}{c}\text { A coleta seletiva melhora o } \\
\text { meio ambiente }\end{array}$ & - & - & 1 & 3 & 6 & 6 \\
\hline & $\begin{array}{l}\text { Participaria da coleta } \\
\text { seletiva se houvesse or- } \\
\text { ganização e estrutura }\end{array}$ & $\begin{array}{c}\text { A participação depende } \\
\text { da aceitação da coleta } \\
\text { seletiva como algo correto } \\
\text { e benéfico }\end{array}$ & - & - & - & 3 & 1 & 2 \\
\hline & $\begin{array}{l}\text { Não participo por falta } \\
\text { de oportunidade e/ou } \\
\text { acomodação }\end{array}$ & $\begin{array}{c}\text { Pessoas que trabalham } \\
\text { fora não têm tempo para } \\
\text { participar da coleta seletiva }\end{array}$ & 3 & 3 & - & - & - & - \\
\hline & $\begin{array}{c}\text { Não participo por falta de } \\
\text { incentivo }\end{array}$ & $\begin{array}{l}\text { A coleta seletiva depende } \\
\text { de incentivo e de informa- } \\
\text { ção para a população }\end{array}$ & 1 & 2 & - & - & - & - \\
\hline & $\begin{array}{c}\text { Não participaria por falta } \\
\text { de tempo }\end{array}$ & - & - & - & 2 & 2 & 1 & - \\
\hline
\end{tabular}

MP: Mata da Praia; JC: Jardim Camburi; PS: Praia do Suá; J: Jucutuquara; IMB: Ilha de Monte Belo; BL: Bairro de Lourdes 
Essa coisa do lixo orgânico, dos descartáveis, até mesmo para o trabalho das pessoas, melhora a seleção do lixo (BL). Eu achei uma coisa bacana. Quando tem vidros, latas, essas coisas que pode cortar o lixeiro porque está tudo misturado. Fica melhor separar logo, né? (IMB).

E o terceiro, que coleta seletiva seria a coleta regular do lixo domiciliar executada pela Prefeitura Municipal (10/48):

Da coleta seletiva? Do caminhão que passa para recolher o lixo todos os dias? A coleta de lixo aqui é boa, não há problema. Quase todo dia tem caminhão de lixo aí, apanha o lixo nas peixarias, tem sempre um varredor de rua também (PS).

Esta situação de desconhecimento foi verificada nos bairros PS, J, IMB e BL onde a coleta seletiva municipal estava sendo implantada. Em todos os bairros houve associação da coleta seletiva com as atividades exercidas pela Prefeitura Municipal, quer sejam identificadas como coleta diferenciada (MP e JC) ou com a coleta regular de RSU (PS, J, IMB, BL). Essa associação está no imaginário da população, pois, no país, a responsabilização municipal pelos serviços de limpeza urbana e resíduos sólidos está na própria Constituição e tem sido exercido por este ente federativo, mesmo quando há serviços concedidos ou terceirizados. Observa-se que, uma parcela da população pesquisada (6/48) mostra-se distanciada do tema coleta seletiva, mas mesmo assim, atribui a responsabilidade pelo seu funcionamento ou não à Prefeitura Municipal.

Coleta seletiva do lixo é o projeto da Prefeitura para separar o lixo que pode ser reciclado. Tenho visto, dentro desse projeto, vários contêineres com lugares específicos, onde a população deve separar o seu próprio lixo (MP).

É interessante destacar que esta visão foi identificada no bairro MP. Neste bairro, a coleta seletiva já estava implantada há vários anos utilizando PEVs para a coleta no local. Na ampliação do projeto, ocorrida em 2002, passou a contar com coleta seletiva operada por cooperativa de catadores. Tal inconsistência denota a insuficiência de ações de divulgação e orientação da população local por parte dos responsáveis pelo programa.

Com relação à participação na coleta seletiva, foram identificados os três grupos propostos na hipótese: um grupo que participa (12/48 dos entrevistados), principalmente nos bairros que apresentam o programa de coleta seletiva mais consolidado (JC e MP); os que estariam dispostos a participar (22/48); e os que não participam (14/48). O discurso coletivo do grupo que afirmou participar evidencia que a maioria das pessoas entende que participar é separar o lixo (10/48); alguns ainda ajudam na divulgação do programa e em trabalhos voluntários (2/48).
Participo. Colocando os lixos de acordo com... se é seco, se é molhado. O que eu acho que pode servir para alguém, eu não misturo, não. Muita coisa que vai para o lixo se aproveita (JC). A gente separa o que é vidro, que é plástico, que é lata, papel. E tem próximo aqui, numa praça... um treco especial para se colocar (MP).

No grupo que declara estar disposto a participar - maior grupo entre os participantes - o principal fator de motivação destacado foi o meio ambiente (16/48):

Me motivaria se fosse um trabalho bem feito, troço mais organizado, direitinho. Saber que estou contribuindo para resolver um problema ecológico (IMB). Saber que esse material que estou separando para a reciclagem não vai ficar poluindo nossos rios, nossas terras (J). É bom para o meio ambiente. É uma coisa que a gente contribuiria para a natureza, de certa forma (BL).

Outra parcela (6/48) participaria em função da organização, o que permite associar tal participação a fatores contingenciais (grupo de participação eventual):

Dependendo de como a administração vem fazendo, a gente também participa. Primeiro tem que saber como é que vai fazer, ser orientado. O convite de alguém né? (J) O que mais me motivaria seria colocar pontos estratégicos, para que não haja bagunça na rua, como lixo esparramado em todo o lugar ou como tem aí (IMB).

O mais importante da coleta seletiva é um local apropriado. É preciso ter um local específico, porque qualquer coisa que você fala em relação à coleta de lixo incomoda a comunidade, se você coloca uma caixa na frente do cara ali, ele pode não gostar porque todo mundo vai jogar lixo ali, entendeu?(J).

A motivação em participar apresenta-se relacionada ao exercício da cidadania, à melhoria da limpeza do bairro, ao problema dos resíduos sólidos, do ambiente e, em menor escala, à geração de empregos. A organização do programa de coleta seletiva também aparece associada à participação.

Sidique, Joshi e Lupi (2010a), ao estudar o perfil de pessoas que utilizam instalações de coleta seletiva nos Estados Unidos, verificaram a tendência ao uso de tais espaços, sempre quando os envolvidos sentem que a reciclagem é uma atividade prática e estão familiarizadas com os locais. Concluem que o sucesso dos programas depende fortemente da participação das famílias nas atividades de triagem.

Aspectos impeditivos e/ou que dificultam a participação da população resultaram na: falta de incentivo, divulgação e 
orientação de como proceder e necessidade de deslocamentos a grandes distâncias para entregar o resíduo separado (6/48).

Participaria sim se não for me locomover demais. Pelo menos, a gente veria o bairro limpo. Isso é uma coisa para a melhoria do bairro; a gente precisa colaborar e também participar (IMB). Eu gostaria que tivesse condições de ser feito, a gente separaria o lixo para colocar nos recipientes adequados. Agora, sair da minha casa para passar para os outros, eu não posso porque eu tenho o meu trabalho (J).

Clarke e Maantay (2006) em estudo sobre as razões da existência de diferentes taxas de participação na coleta seletiva, entre bairros da cidade de Nova Iorque, constataram que fatores como a falta de compreensão do programa por parte dos moradores e a qualidade da infraestrutura e dos serviços de limpeza pública prestados podem afetar negativamente a taxa de participação social. Embora pesquisas do Departamento de Saneamento local apontassem que os residentes das diversas áreas da cidade compreendiam as regras do programa, as taxas de recuperação de materiais para reciclagem variaram substancialmente (9 a $31 \%$ ) entre os distritos, enquanto a média da cidade era de $20 \%$. Relataram ainda que, nos bairros onde a participação era baixa, a maioria dos entrevistados sentia-se inseguro em utilizar os pontos de entrega de recicláveis, salientando que a iluminação era insuficiente, assim como o número de recipientes disponíveis para armazenamento dos recicláveis e a frequência de esvaziamento. Em bairros de elevada participação, os entrevistados relataram o oposto.

No terceiro grupo identificado, caracterizado pela não adesão ao programa nos bairros onde a coleta seletiva já estava implantada desde 1998, verificou-se que a ausência de participação estava associada à falta de oportunidade e/ou acomodação (6/48). "Não sou eu que levo o lixo para a rua. Esse negócio fica lá em casa a cargo da mulher... então, não participo (JC)".

Outro discurso coletivo evidencia que a não participação estaria relacionada à modalidade de coleta seletiva oferecida no bairro:

Falta oportunidade. Só tem uma coleta no bairro... dificulta pra gente. O local que é de coleta seletiva é longe da minha casa. O caminhão que passa em frente à casa não faz a coleta seletiva (MP).

Entretanto, depoimento colhido no mesmo bairro apresenta justificativa diferente:

Fico a maior parte do tempo fora de casa, na hora que o lixeiro passa, eu não estou em casa. A moça que trabalha aqui faz a coleta do meu lixo doméstico. Ela não separa, tem que estar orientando. Eu mesmo não levo lá e não vejo sendo colocado. Sei que vou criar um caso com a minha secretária, se eu pedir para ela ir e ela não for. Nesse caso, nem peço porque sei que é um mal menor (MP).

Outros motivos relacionados a não participação são falta de tempo (5/48) e o custo:

"Pra mim não daria por causa do meu serviço (IMB). E o custo também fica muito caro, porque a pessoa vai comprar quantos centos de sacos de lixo pra botar um em cada um (J)...".

De um modo geral os sujeitos coletivos identificados justificam a não participação devido à falta de oportunidade, de tempo e de incentivo; carência de orientação e à inexistência de infraestrutura. Não se verificou, de forma explícita, a rejeição ao programa de coleta seletiva.

Depreende-se das falas, a ideia de que participar da coleta seletiva é uma atividade trabalhosa, incompatível com a disponibilidade de tempo de quem trabalha fora. Este aspecto entra em conflito com a informação de que participar da coleta seletiva é muito fácil, geralmente difundida para a população por entidades que promovem ações e programas desta natureza.

McDonald e Oates (2003) exploraram as potenciais barreiras à reciclagem de papéis dentro de uma comunidade do Reino Unido, a partir do levantamento das razões que levavam as famílias a não aderirem ao sistema de reciclagem local. Identificaram como principais fatores: falta de espaço para instalar o coletor de recicláveis; pequena geração de resíduos; aparência física do coletor; preferência em doar recicláveis para entidades beneficentes ou a outras iniciativas; e falta de oportunidade e/ou impossibilidade de participar, por diversas razões.

Como causas da descontinuidade dos programas de coleta seletiva em Vitória apareceram a acomodação e o desinteresse da população. Esses fatores estão associados a aspectos culturais e ao nível de instrução do povo brasileiro que, em geral, tem o hábito de jogar lixo no chão, ou seja, não se ligar muito na questão do destino adequado dos resíduos (Tabela 2). O descrédito relativo a ações oriundas do poder público também foi citado. Parte dos discursos coletivos identificados aponta para a necessidade de maior envolvimento com as comunidades, por parte do poder público, como forma de promover a continuidade dos programas. Há consenso que as ações de divulgação e mobilização devem ser contínuas.

$\mathrm{Na}$ oportunidade 20/48 (42\%) dos entrevistados expressaram livremente comentários adicionais sobre a coleta seletiva. Nos comentários encontram-se referências à qualidade de vida associada à limpeza dos bairros e ao fato de que o adequado funcionamento da coleta seletiva seria decorrência da organização e estrutura da coleta regular (Tabela 2). 
Tabela 2 - Descontinuidade de programas de coleta seletiva de resíduos sólidos urbanos e comentários livres sobre a coleta seletiva: síntese das ideias centrais e ancoragem, por bairro

\begin{tabular}{|c|c|c|c|c|c|c|c|c|}
\hline \multirow{2}{*}{ Ideia central síntese } & & \multirow{2}{*}{ Ancoragem } & \multicolumn{6}{|c|}{ Número de entrevistas por bairro } \\
\hline & & & MP $(n=8)$ & $J C(n=8)$ & PS $(n=8)$ & $J(n=8)$ & IMB $(n=8)$ & $B L(n=8)$ \\
\hline \multirow{3}{*}{$\begin{array}{l}\text { Descontinuidade } \\
\text { de programas de } \\
\text { coleta seletiva }\end{array}$} & $\begin{array}{l}\text { Acontece por falta de } \\
\text { interesse e acomodação }\end{array}$ & $\begin{array}{c}\text { A população não dá o } \\
\text { valor devido à coleta } \\
\text { seletiva }\end{array}$ & 4 & 5 & - & 1 & - & - \\
\hline & $\begin{array}{l}\text { Acontece por falta de } \\
\text { educação, conscientiza- } \\
\text { ção e estímulo }\end{array}$ & $\begin{array}{l}\text { O brasileiro tem a } \\
\text { memória curta }\end{array}$ & 4 & 3 & 4 & 2 & 2 & 6 \\
\hline & $\begin{array}{l}\text { Acontece por falta de } \\
\text { estrutura e de divulgação }\end{array}$ & $\begin{array}{l}\text { Falta de continuidade } \\
\text { nos programas de } \\
\text { coleta seletiva }\end{array}$ & - & - & 4 & 5 & 6 & 2 \\
\hline \multirow{5}{*}{$\begin{array}{l}\text { Algo mais a falar } \\
\text { sobre a coleta } \\
\text { seletiva }\end{array}$} & Não teria mais o que falar & - & 5 & 5 & 4 & 4 & 3 & 7 \\
\hline & $\begin{array}{c}\text { Falta divulgação e } \\
\text { estrutura para a coleta } \\
\text { seletiva }\end{array}$ & $\begin{array}{l}\text { Falta divulgação da } \\
\text { coleta seletiva }\end{array}$ & 1 & 2 & - & - & - & 1 \\
\hline & $\begin{array}{l}\text { Falta educação e con- } \\
\text { sciência para a coleta } \\
\text { seletiva }\end{array}$ & $\begin{array}{c}\text { O povo precisa ser edu- } \\
\text { cado sobre a limpeza } \\
\text { da cidade }\end{array}$ & 2 & 1 & - & - & - & - \\
\hline & $\begin{array}{l}\text { A coleta seletiva pode } \\
\text { trazer benefícios }\end{array}$ & $\begin{array}{l}\text { Muita gente sobrevive } \\
\text { do lixo }\end{array}$ & - & - & 4 & 2 & 4 & - \\
\hline & $\begin{array}{l}\text { Falta estrutura para a } \\
\text { coleta seletiva }\end{array}$ & $\begin{array}{l}\text { A Prefeitura não atende } \\
\text { a todos os bairros com } \\
\text { a coleta seletiva }\end{array}$ & - & - & - & 2 & 1 & - \\
\hline
\end{tabular}

MP: Mata da Praia; JC: Jardim Camburi; PS: Praia do Suá; J: Jucutuquara; IMB: Ilha de Monte Belo; BL: Bairro de Lourdes

Na visão dos entrevistados a descontinuidade de programas de coleta seletiva estaria associada à: falta de interesse e acomodação (10/48):

Acontece porque as pessoas não participam, não dão valor! A maioria do povo brasileiro é bastante relaxada! O povo não continua tudo que começa, tem o incentivo de se iniciar, daí a pouco aquilo para, o povo parece que não tem aquela vontade de ver coisas bonitas (JC). Falta à pessoa arrumar um tempo para separar e levar no local onde é feita a coleta. A pessoa se acomoda muito fácil com as coisas, né? Os catadores passam e pegam papelão, plástico que interessa e o morador vai ficando acomodado. Estão trabalhando direitinho, né? Coletando o lixo. O povo não respeita, fica tudo sujo, o povo é culpado, né? (MP).

À falta de educação, conscientização e estímulo (21/48):

"Não há muita colaboração. As pessoas pensam assim: Ah! A gente já paga os impostos, o lixo tem mais é que jogar de qualquer jeito. Acomodação das pessoas, né? (BL)”.

A coleta seletiva já é uma coisa mais complicada. Se uma pessoa não tem preparo pra pegar o lixo que ela tem e jogar na lata, para ele jogar numa coleta seletiva vai ser muito mais difícil ainda (J). A pessoa começa e depois se acomoda! Tem que ser feito com amor e com capricho, as coisas andam, mas se começar a relaxar acaba (IMB).
O brasileiro é muito acomodado e preguiçoso para separar os negócios. Depende do povo, né? As autoridades têm que incentivar e não deixar passar no esquecimento (PS). Falta de estímulo do poder público (JC). Tudo que você faz e não dá corda, até o relógio para. Então a coleta de lixo está fadada a não ser bem sucedida se não houver um encaminhamento nesse sentido. Um estímulo (MP).

E à falta de estrutura e divulgação (17/48):

"Não houve orientação adequada (PS). No momento em que é colocada a lixeira da prefeitura, as pessoas podem até ter um incentivo para fazer essa coleta (BL)".

O povo não está conscientizado. Talvez porque não foi divulgado o resultado, o benefício (IMB). É responsabilidade do poder público local, principalmente o municipal, e não pode deixar ao esquecido, basta dizer que o brasileiro tem memória curta. Falta organização, o pessoal acaba desistindo. A Prefeitura não dá assistência, culpo mais a Prefeitura (J).

As questões resultantes sobre a descontinuidade reforçam alguns aspectos apresentados anteriormente, em especial quanto à insuficiência de ações de mobilização, divulgação e informação à população, por parte do poder público. Tais resultados estão coerentes com os estudos de Sidique, Joshi e Lupi, (2010a). Nas 
entrevistas houve, inclusive, menção a um aspecto importante que é o retorno dos resultados aos participantes. A divulgação dos resultados alcançados, de modo objetivo, claro e acessível à população, contribui para a transparência do programa e é ponto estratégico para criar confiabilidade e garantir a participação social. A devolutiva dos benefícios obtidos, do número de pessoas envolvidas e beneficiadas com tais atividades e, principalmente, o destino dos recursos auferidos sensibilizam e motivam a continuidade ou o ingresso de novos participantes em programas sociais dessa natureza. Os depoimentos obtidos reforçaram percepções identificadas em pergunta anterior, como a falta de divulgação e de estrutura para a coleta seletiva (4/48):

Falta divulgação. Falta fazer propaganda melhor. Aqui a Prefeitura colocou essa separação, mas não teve muita divulgação. Eu acho que deveria ter um projeto para continuar, porque isso é importante (BL). O comércio está colocando nas caixinhas, mas está faltando propaganda, falar mais para as pessoas (JC). Acho que seria uma boa para a comunidade, já tem condominio que está usando a coleta seletiva para fins lucrativos (JC). Poucos contêineres. Se tivesse um aqui na esquina ficaria mais fácil, eu mesmo colocaria no carro para levar, é coisa para se programar (MP).

A falta de educação e de consciência para a coleta seletiva (3/48):

O povo ainda não tem educação, de estar respeitando o horário do lixo, de estar ensacolando, até mesmo amarrando o seu lixo para evitar doenças. É importante a Prefeitura estar fazendo junto com a comunidade um trabalho de conscientização (JC).

O pessoal da rua suja a rua, a prefeitura varre e varre, mas não adianta porque o povo não tem educação. É feita a coleta seletiva e as próprias pessoas de rua abrem as comportas e derrubam esse lixo todo, onde dificulta a limpeza (MP)

E a falta de estrutura para a coleta seletiva (3/48):

Tem aí algumas coisas com relação à coleta seletiva espalhada na nossa ilha. Alguns bairros têm, outros não. A coleta seletiva, assim como o lixo também tem que ter um lugar específico público, não em frente da minha casa! (J).

A gente vê que a coleta do lixo normal já é tão dificultosa, então essa coisa do seletivo seria um pouco mais ainda, então a gente deveria partir do princípio de organizar essa coisa da coleta normal, para depois partir para um projeto maior (IMB)
Os discursos coletivos obtidos permitiram ainda identificar a ideia central de que a coleta seletiva pode trazer benefícios (10/48):

Essa classificação... eu acredito que temos muito que ganhar ... uma qualidade de vida melhor. As próprias pessoas deviam se interessar mais um pouquinho para melhorar, porque começa deles mesmos (PS). É uma coisa importante, essa coisa assim do meio ambiente, que poderia se colocado em prática. Muita gente até sobrevive desse lixo, né?(J) Posso falar sobre os ratos também, a gente tá aqui num tormento danado (IMB).

Verifica-se que a coleta seletiva é vista como algo benéfico e a insuficiência das ações de divulgação e mobilização é, mais uma vez, destacada. Nos bairros de implantação da coleta seletiva municipal, os discursos reforçam a expectativa positiva em relação ao programa.

Nos discursos dos participantes nota-se a menção às categorias de coleta: coleta seletiva por PEVs e porta a porta. A coleta seletiva por organização de catadores autônomos, realizada por uma associação de catadores apoiada pela Prefeitura, não foi citada. Encontram-se alguns comentários sobre catadores informais, para os quais os resíduos sólidos seriam uma forma de sobrevivência. Ainda persiste a visão de que a atividade de catador não é uma profissão e sim uma busca de sobrevivência para pessoas que estão à margem da sociedade; como não há organização, não a associam à coleta seletiva.

\section{Conclusões}

Diversas percepções e comportamentos dos entrevistados em relação à participação social em programas de coleta seletiva foram identificados, assim como os fatores de motivação para tal participação. Fatores de motivação importantes são: o meio ambiente e a qualidade de vida associados à melhoria da limpeza urbana; a redução do perigo, representado pela manipulação e disposição inadequada de RSU, à população e ao pessoal que trabalha na limpeza urbana; a organização e a adequação da estrutura operacional implantada para dar suporte ao programa; e a existência de ações continuadas de divulgação, mobilização e informação.

Aspectos impeditivos ou que dificultam a participação da população seriam: falta de divulgação dos resultados da coleta seletiva; acomodação e desinteresse da população; nível cultural e de instrução do povo brasileiro; descrédito relativo a ações oriundas do poder público; falta de espaço para armazenar resíduos recicláveis nas residências; necessidade de limpar previamente as embalagens para evitar problemas com insetos e odores desagradáveis durante o armazenamento; e tempo gasto 
e trabalho dispendido para a separação dos recicláveis. Os principais aspectos que impedem ou dificultam a participação da população na coleta seletiva estão associados à ausência dos fatores de motivação identificados.

De um modo geral, os resultados referentes à participação social nos PCS em Vitória indicam que a população do município:

- Conhece o termo coleta seletiva e faz sua associação com a questão dos resíduos sólidos;

- Tem noção de que muitos materiais presentes nos resíduos sólidos poderiam ser reaproveitados;

- Considera a coleta seletiva importante. Há expectativa positiva em relação aos programas e a maioria dos entrevistados está predisposta para participar;

- Em geral, considera a coleta seletiva dos resíduos sólidos urbanos como responsabilidade do poder público (da Prefeitura Municipal);

- Associa a coleta seletiva à economia de recursos financeiros pelo município e/ou a lucro;

- Em sua grande maioria, entende como participação no programa municipal de coleta seletiva apenas a ação de separar os resíduos sólidos que produz. Há um grupo menor disposto a ajudar na divulgação e em trabalhos voluntários.
O estudo permitiu, ainda, verificar a adequação da classificação da população alvo de programas de coleta seletiva em três grupos: cativo, de participação eventual e que não participa, confirmando a hipótese proposta. Esta classificação pode ser considerada na tomada de decisão com relação à implantação de novos programas ou na readequação de programas existentes de coleta seletiva de resíduos sólidos.

Considerando-se que a participação voluntária da população nos programas de coleta seletiva é baixa, mas que pode aumentar em longo prazo e que a participação efetiva (grupo cativo) tende a crescer gradativamente na medida em que também se incrementem ações mobilizadoras, o que implica dizer que há mobilidade entre os diferentes grupos identificados, recomendase a implementação de mecanismos adicionais para sensibilização e mobilização social. A aprovação da Política Nacional de Resíduos Sólidos, com suas diretrizes, objetivos e instrumentos e o que isso pode vir a representar para o setor, pode ser um mote. A existência de canais diretos de comunicação com a população, o registro formal de dados, sua sistematização e a devolutiva à comunidade, como também a realização periódica de pesquisas de opinião são instrumentos que podem e devem ser incorporados como rotina em programas dessa natureza.

\section{Referências}

BRASIL. Ministério das Cidades. SNIS. Diagnóstico do manejo de resíduos sólidos urbanos. (2007). Disponível em: < http://www.snis. gov.br>. Acesso em: 17 jun. 2010.

Lei $n^{\circ}$ 12.305, de 2 de agosto de 2010. Institui a Política Nacional de Resíduos Sólidos e dá outras providências. Disponível em: <http://www.planalto.gov.br/ccivil_03/_ato2007-2010/2010/lei/ |12305.htm>. Acesso em: 18 ago. 2010.

BRINGHENTI, J.R. Coleta seletiva de resíduos sólidos urbanos: aspectos operacionais e da participação da população. Dissertação (Doutorado) - Faculdade de Saúde Pública, Universidade de São Paulo, São Paulo, 2004

CARDOSO, R.H. Isto é política? Novos Estudos CEBRAP, v. 20, p. 74-80, 1988.

CEMPRE. Pesquisa CICLOSOFT. [site]. CEMPRE, Brasil, 2010. Disponível em: <http://www.cempre.com.br>. Acesso em: 18 set. 2010.

CLARKE, M.J.; MAANTAY, J.A. Optimizing recycling in all of New York City's neighborhoods: using GIS to develop the REAP index for improved recycling education, awareness, and participation.
Resources, Conservation and Recycling, v. 46, n. 2, 128-148, 2006.

GOHN, M.G. Teorias sobre os movimentos sociais. São Paulo: Loyola, 2000

JACOBI, P.R. Cidade e meio ambiente: percepções e práticas em São Paulo. São Paulo: Annablume, 2000.

LEFÈVRE, F.; LEFÈVRE, A.M.C. O discurso do sujeito coletivo: um novo enfoque em pesquisa qualitativa (desdobramentos). Caxias do Sul: UDUCS, 2005. 256 p.

MCDONALD, S.; OATES, C. Reasons for non-participation in a kerbside recycling scheme. Resources, Conservation and Recycling, v. 39, n. 4 , p. $369-385,2003$.

RIBEIRO, L.M.; JACOBI, P.R.; BESEN, G.R. et al. Coleta seletiva com inclusão social: cooperativismo e sustentabilidade. São Paulo: Annablume, 2009

SCHERER-WARREN, I. Movimentos sociais e participação. In: SORRENTINO, M. (Coord.). Ambientalismo e participação na contemporaneidade. São Paulo: EDUC/FAPESP, p. 41-56, 2001. 
[SEDU] Secretaria de Desenvolvimento Urbano. Avaliação técnicoeconômica e social de sistemas de coleta seletiva de resíduos sólidos urbanos no Brasil. Brasília: SEDU, 2002.

SEMMAM. Projeto de Ampliação e Modernização da Coleta Seletiva. Programa Vitória Reduz e Recicla - Vitória: Secretaria Municipal de Meio Ambiente, 2002.

SIDIQUE, S.F.; JOSHI, S.V.; LUPI, F. The effects of behavior and attitudes on drop-off recycling activities. Resources, Conservation and Recycling, v. 54, n. 3, p. 163-170, $2010 a$.
Factors influencing the rate of recycling: an analysis of Minnesota counties. Resources, Conservation and Recycling, v. 54, n. 4, p. $242-$ 249, 2010b.

TIMLETT, R.E.; WILLIAMS, I.D. Public participation and recycling performance in England: a comparison of tools for behaviour change. Resources, Conservation and Recycling, v. 52, n. 4, p. 622-634, 2008.

WANG, F.S.; RICHARDSON, A.J.; RODDICK, F.A. Relationships between set-out rate, participation rate and set-out quantity in recycling programs. Resources, Conservation and Recycling, v. 20, n. 1, p. 1-17, 1997. 